\title{
DEBATES
}

\section{Diferenças e aproximações dos leitores da imprensa nacional e regional}

\author{
Differences and approaches from the readers of national and \\ regional press
}

\section{Eduardo Nunomura}

\section{Resumo}

A interiorização da economia no Brasil e a política de descentralização das verbas publicitárias oficiais têm despertado maior interesse dos pesquisadores sobre a mídia regional ou local. Mas estudos acadêmicos costumam se valer de levantamentos nos quais a realidade de regióes mais ricas e populosas é projetada como um retrato de toda a mídia brasileira. Com acesso à base de microdados, será apresentado um recorte sobre os leitores de jornais impressos dentro da Pesquisa Brasileira de Mídia (PBM) nas ediçôes de 2014 e 2015, publicadas pela Secretaria de Comunicação Social da Presidência da República. Inédita por sua representatividade, a PBM revela os hábitos de consumo de mídias de 18.312 brasileiros. Para este artigo, optou-se por um corpus com 4.064 e 3.766 entrevistas, respectivamente. A presente análise evidencia que há distinçóes significativas na forma como os leitores consomem mídias nos principais centros urbanos e fora deles.

\section{Palavras-chave}

Mídia Regional; Jornalismo Local; Imprensa Nacional; PBM.

\begin{abstract}
The economic growth in rural Brazil and the decentralization policy of official funds for propaganda have attracted more interest from researchers on regional or local media. Academic studies use surveys to project the reality of the richest and most populous regions as a reflection of the entire Brazilian press. With access to a microdata base, a first reading on the main results of the Brazilian Media Research (PBM, in Portuguese), in its two editions, 2014 and 2015, will be presented. Published by the Department of Social Communication of the Presidency, the PBM reveals the media consumption habits of 18.312 Brazilians, a representative sample of the population. This article works on a subset of 4.064 and 3.766 interviews. This study shows that there are large differences in the way readers consume media in major urban centers and elsewhere.
\end{abstract}

\section{Keywords}

Regional Media; Local Journalism; National Press; PBM. 


\section{Introdução}

Nos últimos anos, o Brasil vem sofrendo transformaçôes de natureza estrutural em todas as áreas. A interiorização da economia é uma dessas consequências, que leva à constituição de um mercado regional em franca expansão. Dados do Instituto Brasileiro de Geografia e Estatística (IBGE, 2012) apontam que o Produto Interno Bruto (PIB) brasileiro cresceu 197\% entre 2002 e 2012. Sáo Paulo e Rio de Janeiro registraram expansão de $175 \%$ e $194 \%$, portanto abaixo da média nacional. Já Espírito Santo, Mato Grosso, Maranhão e Rondônia quadruplicaram seus PIBs estaduais. As regiôes Norte, Nordeste e Centro-Oeste cresceram acima do que Sul e Sudeste.

A desproporção das economias, contudo, persiste. São Paulo, embora tenha tido o segundo pior crescimento de 2002 a 2012, e só perdendo para o Rio Grande do Sul, possuía um PIB de 1,4 trilhão de reais. Apenas se for somado o PIB dos 17 Estados que tiveram maior expansão nesse período, se pode ultrapassar a economia paulista. Ainda seráo precisos anos ou décadas de crescimento regional para se chegar a uma distribuição mais equânime da riqueza.

O desequilíbrio regional por décadas criou e alimentou o estereótipo de um país conduzido por uma só locomotiva, o Estado de Sáo Paulo, secundada por um vagáo de apoio, o Rio de Janeiro. De forma natural e, por que não, esperada, essas duas ricas metrópoles ocuparam o espaço de centro da economia. Os bons empregos, as melhores universidades, os serviços que funcionam, as oportunidades, enfim, tudo deveria estar nelas. No campo científico, as pesquisas também acabaram se concentrando no eixo Rio-Sáo Paulo.

$\mathrm{E}$ isso não foi diferente na comunicação. As sedes das maiores emissoras de TV, dos jornais de circulação nacional, das rádios de maior audiência, dos grandes portais de internet, das principais agências de publicidade, a quase totalidade delas fica no Rio ou em São Paulo. Essa concentração midiática implicou e ainda implica em um forte desbalanceamento nos estudos ligados à comunicação brasileira. Com frequência, toma-se a parte pelo todo.

A crescente regionalização da economia brasileira e o advento das tecnologias de comunicação permitem que antigas assimetrias de produção jornalística sejam reduzidas ou até eliminadas. Praticamente, não há mais obstáculos técnicos intransponíveis que impeçam que a qualidade de um jornal do interior seja igual ou superior à de um diário do Rio de Janeiro ou de São Paulo. E isso já vem ocorrendo, com veículos regionais ou locais se destacando em prêmios jornalísticos, apenas para citar um termômetro de qualidade. 
Essa realidade, contudo, é ainda mal percebida no meio acadêmico. Impera uma concentração de trabalhos científicos sobre veículos de comunicação de circulação nacional, notadamente os jornais Folha de S. Paulo, O Globo e O Estado de S. Paulo, o Jornal Nacional, da TV Globo, e a revista Veja, da Editora Abril. O risco é projetar cenários, formular teses e criar diagnósticos para todo o sistema midiático do Brasil a partir de perfis de leitores que dizem respeito apenas ao grupo de pessoas que consomem essas "grandes" mídias produzidas no eixo Rio-São Paulo.

Nos estudos que tratam das mídias, o público é considerado, na maioria das vezes, como constituinte da instância de recepção. Se já são escassos os trabalhos da academia em relação a estudos de recepção e/ou de hábitos de consumo de mídia de maneira geral, para a realidade interiorana são ainda mais raros. Empresas especializadas em pesquisas desse gênero são voltadas para o mercado publicitário. As suas análises tentam definir os perfis de leitores para os jornais impressos em função de classes sociais, renda, faixa etária, locais de residência, entre outras categorias. Mas acabam por trabalhar com amostras significativas de cidades mais ricas e populosas e deixando de lado boa parte do resto do país. Acontece que menos de um terço dos brasileiros vivem em cidades cuja população supera os 500 mil habitantes, segundo dados do último Censo (IBGE, 2010).

Para preencher essa lacuna, a Secretaria de Comunicaçáo Social (Secom) da Presidência da República publicou a Pesquisa Brasileira de Mídia (PBM) (BRASIL, 2013 e 2014), cuja principal característica é a representatividade nacional de sua amostra. Já foram publicadas as edições de 2014 e 2015. O presente artigo trabalha com a microbase de dados das duas pesquisas, fornecidas pela Secom. Por meio dela, foi possível identificar diferenças e aproximaçóes entre o público de leitores da imprensa de circulação nacional versus o dos jornais regionais e locais. Pode-se, por exemplo, cruzar informaçóes acerca das formas como os brasileiros se relacionam com os meios de comunicação - incluindo as novas tecnologias de informaçáo e comunicação -, e os contrastes entre os padrôes de uso dos meios de comunicação de massa.

\section{A esquecida midia regional}

Patrick Charaudeau (2012) afirma que a instância de recepção é constituída de um conjunto impreciso de valores ético-sociais e afetivos-sociais, obrigando a instância midiática a apresentar informaçóes que procurem, na medida do possível, corresponder às expectativas de seu público (leitor, ouvinte ou telespectador). No caso dos jornais, foco deste artigo, as empresas de comunicação oferecem notícias aos seus leitores com a perspectiva de que eles as considerem úteis o suficiente para 
despertar o interesse e, posteriormente, ser consumidas. O objetivo, não oculto, é o de rentabilizar seu produto da melhor forma possível.

Neste sentido, ela (a instância midiática) precisa conhecer os comportamentos e as opinióes do público e para isso recorre a dois tipos de técnicas: as que permitem medir o sucesso de uma programação por meios eletrônicos, o que, na França, é chamado de 'audimat', e as que permitem observar os efeitos produzidos pela maneira de tratar tal ou qual programa, os chamados 'estudos de impacto' (CHARAUDEAU, 2012, p. 82)

O autor afirma que estudos baseados nas duas técnicas geram respostas que ainda são tão fragmentárias e pouco verificáveis. Pode-se dizer que ainda permanecem como "incógnitas". Ao se estudar a instância de recepção, é (ou seria) fundamental diferenciar com maior precisão as mídias (nacional e regional ou local) e seus diferentes públicos. Embora seja maioria e atinja um público superior, a mídia regional ou local é alvo de menor atenção dos estudos. Só a partir da segunda metade dos anos 1990, como demarcou Peruzzo (2005), os pesquisadores demonstraram maior interesse pela temática. E isso não é obra do acaso, mas consequência do desenvolvimento das comunicaçóes no país, que mimetizava a distribuição desigual da renda, acabando por centralizar suas produçóes nos grandes centros urbanos.

Pinto (2013), em revisão da literatura científica sobre mídias regionais, apontou que este objeto de estudo possui dois tipos de abordagens. A primeira referencia à mídia regional, a partir do que se concebe como parâmetro de qualidade, o jornalismo praticado pelos grupos midiáticos do Sudeste, sobretudo nas capitais do Rio de Janeiro e Sáo Paulo. E a segunda, diametralmente oposta, supervaloriza veículos e/ou grupos em determinadas áreas geográficas do país. "A mídia regional é apontada como elo mais fraco numa comparação com a mídia de referência nacional. Pouco se avança além das constataçôes da propriedade e dos vínculos políticos", aponta Pinto (2013, p. 100). Mas como frisa Peruzzo:

A mídia local se ancora na informação gerada dentro do território de pertença e de identidade em uma dada localidade ou região. Porém, ela não é monolítica. Não há uniformidade no tipo de vínculo dos meios de comunicação em suas regiốes, pois a inserção (mais ou menos) comprometida localmente depende da política editorial de cada veículo (PERUZZO, 2005, p. 76). 
Anamaria Fadul (2006) vê progressos, apesar das dificuldades, para a mídia regional nos últimos anos, já que a descentralização econômica favorece a criação de um ambiente mais propício para a expansão dos negócios. "Essa situação despertou inicialmente o interesse das agências de publicidade, dos anunciantes e dos veículos de comunicação que, apesar das dificuldades econômicas enfrentadas, estáo descobrindo oportunidades de negócios em outras regiōes do país" (FADUL, 2006, p. 24).

É diante dessa pluralidade de vozes das regiôes que se tornam questionáveis generalizaçóes antes de uma análise mais aprofundada. Na visão de Pinto (2013), a mídia brasileira pode ser vista levando em conta a perspectiva dos sistemas, entendidos como a reunião de elementos em interação. Essa distinção é relevante porque permite compreender o sistema midiático a partir da perspectiva relacional e interacional estabelecida entre os sistemas de referência nacionais e as diversas formas de sistemas regionais neles encontrados. "Entendemos os sistemas regionais como subsistemas autônomos integrantes do sistema midiático brasileiro, que uma vez agrupados expliquem sua dinâmica”, pontua Pinto (2013, p. 104).

A autora propõe analisar esse grande sistema midiático a partir de sua categorização em três outros subsistemas, constituídos pelos "supraestaduais" (os veículos de referência nacional), "estaduais" (na maioria das vezes, feitos nas capitais e distribuídos nas cidades do entorno) e "subestaduais" (com cobertura pontual em alguns municípios). Cada grupamento tem uma relação distinta com seu mercado e com os laços políticos locais, apenas para citar duas variáveis. E esta dinâmica envolve as inúmeras e distintas variáveis que permeiam as instâncias midiáticas e de recepção em cada localidade. Compreender esse processo é mandatório. A mídia continua se envolvendo ativamente na construção do mundo social, como sublinha Thompson (2014, p. 156), porque "modela e influencia o curso dos acontecimentos, cria acontecimentos que poderiam não ter existido em sua ausência”.

\section{A dimensão da Pesquisa Brasileira de Mídia}

Em fevereiro de 2014, a Secretaria de Comunicação Social (Secom) da Presidência da República publicou, pela primeira vez, a PBM 2014: Hábitos de Consumo de Mídia pela População Brasileira (BRASIL, 2013). O estudo foi realizado a partir de amostras dos 26 Estados e o Distrito Federal com 18.312 brasileiros, e conduzido por 200 pesquisadores em 848 municípios entre 12 de outubro e novembro de 2013. Em janeiro de 2015, o governo divulgou a segunda edição, de igual dimensão e com trabalho de campo realizado entre os dias 5 e 22 de 
novembro de 2014, abrindo a possibilidade de avaliar mudanças no comportamento de consumo de mídia pela população (BRASIL, 2014).

A PBM, no que tange à sua abrangência, garante "a representatividade do universo da população brasileira de 16 anos ou mais de idade" (BRASIL, 2013, p. 14). Os bancos de dados de 2014 e 2015 possuem cerca de 2 milhóes de células, cada um. A pesquisa permite traçar um diagnóstico de como as mudanças tecnológicas e comportamentais afetam a utilização dos meios de comunicação no país. Pode-se, por exemplo, descobrir as formas como os brasileiros vêm se informando e o grau de confiança deles em relação às diversas fontes de notícias ou o uso da internet. Os dois relatórios já publicados tiveram como inspiração estudos como os conduzidos pelo European Social Survey e o Latin American Public Opinion Project.

Para este artigo, o corpus de pesquisa analisa os microdados das PBMs $2014 \mathrm{e}$ 2015, solicitados diretamente à Secom. Isso significa que os resultados aqui apresentados não só vão além do que já foi tornado público na divulgação dos relatórios - e noticiados pelos principais veículos de comunicação - como tratam de focar sua atenção a um recorte específico, o dos jornais impressos. A partir dos microdados, será feita uma comparação entre dois grupamentos distintos de veículos de comunicação: a imprensa de circulação nacional (Folha de S. Paulo, O Globo e O Estado de S. Paulo) e os demais jornais citados pelos entrevistados, sendo eles regionais ou locais.

Para o desenho amostral das PBMs, a equipe da Secom utilizou os dados do Censo de 2010 e da Pesquisa Nacional por Amostra de Domicílio (PNAD) 2011 do IBGE. Na construção das amostras estaduais, foram sorteados os municípios e dentro deles os setores censitários. Neste conjunto, os pesquisadores selecionavam os entrevistados utilizando cotas proporcionais segundo as variáveis de sexo, idade, instrução e ramo de atividade. Chegou-se, assim, a dados com margem de erro máxima de um ponto percentual para mais ou para menos, assumindo intervalo de confiança de $95 \%$. Para os estados, as margens de erro variam de $2 \%$ a $4 \%$, dependendo do número de entrevistas, com o mesmo intervalo de confiança (BRASIL, 2014, p. 11).

Ainda assim é importante frisar que este artigo foi elaborado tendo ciência da ressalva que o próprio relatório da $\mathrm{PBM}$ faz em relação a uma possível subdimensão do uso dos dados de jornais impressos e rádios (BRASIL, 2013, p. 11). Isso porque, de forma ideal, o levantamento deveria trabalhar com amostras maiores e mais representativas de cada microrregião, em vez de um número limitado de entrevistados em algumas localidades. Jornais impressos e rádios costumam ter alcance sobre um número pequeno de municípios e em poucos casos todo o Estado. Já as mídias TV, 
internet e, um pouco menos, revista, possuem alcance mais amplo e global. Para evitar distorçôes de análise, optou-se por ignorar extrato de dados do corpus que revelassem discrepâncias elevadas em relação às descobertas encontradas para a totalidade dos jornais analisados nos dois relatórios gerais da Secom. A manipulação da base de dados da PBM foi realizada com o software PASW Statistics 17 (antes conhecido como SPSS Statistics), da empresa IBM.

Por último, mas não menos importante, cabe ressaltar que este estudo faz parte de uma pesquisa de âmbito maior no qual serão problematizadas outras questóes subjacentes aos resultados apontados neste artigo. No limite do avanço que o estudo mais amplo permite, serão apresentadas aqui algumas hipóteses explicativas para os resultados distintos que verificou haver entre a imprensa nacional e a regional.

\section{O que os microdados revelam}

Um quarto dos leitores de Folha de S. Paulo, O Globo e O Estado de S. Paulo já preferem a versão digital das ediçôes diárias. Metade deles lê um desses três jornais de 4 a 7 dias por semana. Um terço tem o hábito de ler outro jornal regional ou local, seja de segunda a sexta-feira ou aos sábados e domingos. Para as versóes impressas, mais da metade compra esses títulos nas bancas ou por meio de assinaturas. Durante os trabalhos de campo dos pesquisadores, entre outubro e novembro de 2013 e novembro de 2014, as pautas mais lidas por esse público foram de política, cidades, esportes e economia.

Já oito em cada dez leitores de jornais regionais ou locais não abandonaram a versão impressa, sendo que metade deles compra as ediçóes nas bancas. Um quinto deles lê o noticiário dessas publicaçóes pelas mãos de outra pessoa, em bibliotecas, consultórios, ou no trabalho. A assinatura de jornais nos interiores e periferias brasileiras é um luxo para menos de $9 \%$ dos leitores. Os brasileiros das regióes fora do eixo Rio-São Paulo são mais fiéis ao diário regional ou local preferido, não consumindo os jornais nacionais mesmo que em alguns dias da semana. Nos meses de outubro e novembro de 2013 e novembro de 2014, cidades, esportes, classificados e notícias policiais foram os cadernos preferidos desse público.

Por essa pequena introdução sobre os dados das PBMs 2014 e 2015, que fazem parte do corpus deste artigo, percebe-se que há divergências significativas entre esses dois grupamentos de leitores - ao longo desta seçáo, serão apresentadas em maiores detalhes, assim como serão apontadas as congruências. Os tipos de consumidores de jornais, os impactos que seu noticiário produz, a percepçáo deles em relação a questôes locais ou nacionais, as formas e os hábitos de uso das mídias, há inúmeros pontos que distinguem o público-leitor de grandes metrópoles como São 
Paulo e Rio com o do resto do país. Compreender se há, e quais são, as especificidades na leitura da imprensa regional e local revela uma necessidade de se aprofundar pesquisas científicas com um olhar específico para esse tema, uma vez que aquelas realizadas sobre os jornais de circulação nacional estáo longe de representar um retrato para toda a imprensa brasileira.

Para a amostra deste corpus, foram coletados dados de 4.064 pessoas na pesquisa de 2014 e de 3.766 na de 2015 que mencionaram pouco menos de 400 publicaçóes $^{1}$. Esses dois conjuntos foram extraídos por terem citado o jornal impresso como o meio de comunicação preferido para se informar. Na primeira edição da pesquisa, 228 (5,6\% do total) citaram Folha de S. Paulo, O Globo ou O Estado de S. Paulo (doravante denominados de "imprensa nacional") em primeiro lugar e 3.836 $(94,4 \%)$ os demais veículos analisados ("imprensa regional ou local”). No ano seguinte, essa amostra apresentou proporçóes diferentes. Um total de 342 leitores $(9,1 \%)$ apontou a imprensa nacional como seu meio de comunicaçáo preferido e $3.424(90,9 \%)$ a imprensa regional ou local.

Uma das questôes que merecem ser exploradas, inicialmente, é qual o veículo que o entrevistado considerava mais informativo. Observa-se no gráfico abaixo que mais da metade dos leitores das imprensas nacional e regional ou local responderam a televisão e depois a internet. Quase 30\% de leitores já consideram que a rede mundial de computadores informa mais sobre o Brasil que os jornais.

\footnotetext{
${ }^{1} \mathrm{Na}$ base de microdados da PBM, foram citados 1.555 jornais. Em ambas as pesquisas (2014 e 2015), os nomes foram mencionados de forma espontânea pelos entrevistados. Este artigo trabalha com um número menor de títulos por ter delimitado seu corpus apenas às pessoas que citaram ser o jornal seu veículo de preferência.
} 
Gráfico 1 - Onde se informa mais sobre o Brasil

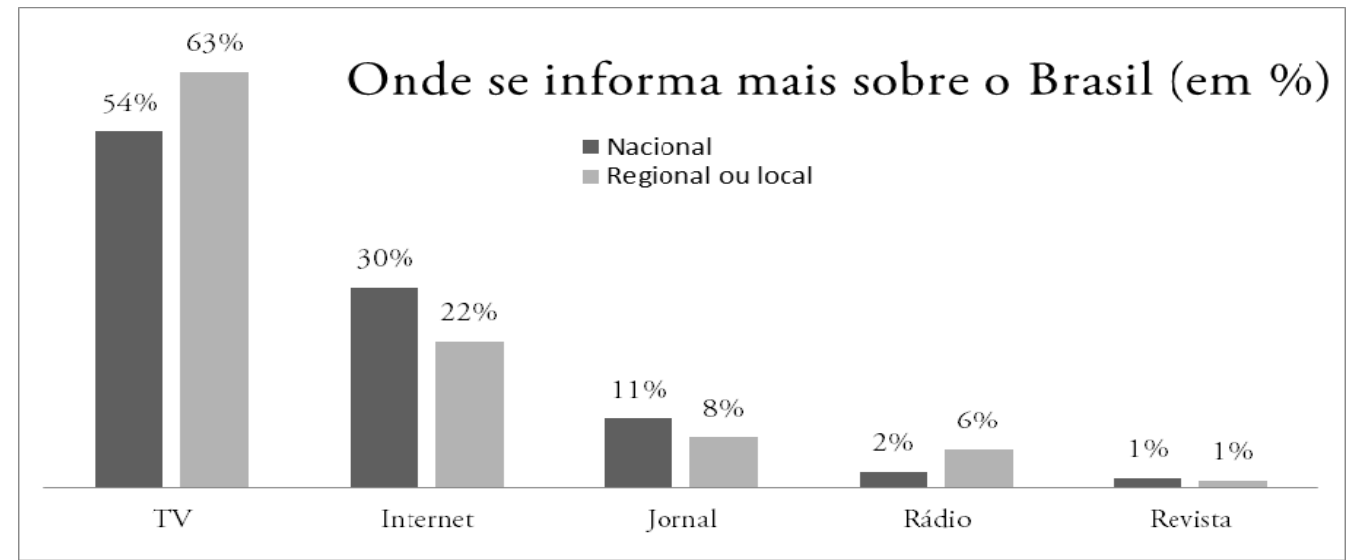

Fonte: Pesquisa Brasileira de Mídia 2015 (BRASIL, 2014).

Se já era esperada a supremacia da TV sobre as demais mídias, a permanência da internet na segunda posição (repetindo a tendência da pesquisa em 2014) e com o triplo, e até o quádruplo, de citações que as das publicações impressas diárias, reforça a necessidade de os jornais repensarem seus produtos. Fabbri Júnior (2006, p. 137) já alertava: "A internet traz um novo desafio para as empresas e profissionais de comunicação. E, ao mesmo tempo em que representa uma ameaça, também se mostra um leque de novas oportunidades, criando um cenário cada vez mais competitivo". Uma das preocupaçóes constantes dos departamentos comerciais das empresas é a não renovação das assinaturas de jornais, o que implica reduzir a base de consumidores, diminuindo assim seu poder de atração para o setor publicitário. Esses dados da PBM mostram que há uma tendência de o leitor de jornal estar perdendo o interesse pela sua mídia preferida.

Na PBM 2014, o entrevistado apontava quantas horas costumava dedicar de seu tempo para ler os jornais. Metade do público dos interiores ou periferias gastava menos de uma hora diária. Já $63 \%$ dos leitores da imprensa nacional despediam acima de 1 hora por dia. Uma explicação se deve ao fato de que a imprensa nacional entrega um produto com maior quantidade de páginas do que um regional ou local (o primeiro caderno de Folha de S. Paulo, O Globo e Estadão já equivale a um diário inteiro de outras praças), o que faz com que o leitor dedique mais tempo para o 
hábito de ler. No ano passado, essa questão não foi aplicada novamente ${ }^{2}$, tornando impossível fazer uma comparação sobre esse item.

A PBM 2015 introduziu novas questóes. Uma pergunta indagava ao entrevistado por qual motivo ele lia o jornal, oferecendo algumas possíveis respostas. Duas delas saltam aos olhos. Perguntados se o jornal servia para lhe informar ou saber das notícias, menos de um terço deles respondiam que sim - a grande maioria dizia que essa pergunta não se aplicava para a sua situação. E em outra questão os veículos, na opinião dos entrevistados, falham ao servir como instrumento de aprendizado ou educação. Quase metade deles disse que Folha de S. Paulo, O Globo ou O Estado de S. Paulo não serviam para estudar ou aprender, acima da média de 40,8\% dos que também responderam negativamente entre os leitores dos jornais regionais ou locais.

Ao comparar um quesito relevante em relação à credibilidade do veículo, percebe-se que aumentou o porcentual de pessoas que confiam nas imprensas nacional e regional ou local no intervalo de um ano entre as duas pesquisas. Passou de $52,2 \%$ para $60,5 \%$ os que responderam que confiam nas notícias dos três grandes jornais de circulação nacional e de 54,6\% para 60,6\% no noticiário da imprensa fora do eixo Rio-São Paulo. Importante ressaltar que essa elevação ocorreu em um ano eleitoral com uma disputa extremamente acirrada.

Os dois dados anteriores, contudo, sugerem uma divergência. Poucos responderam que os jornais servem como veículos informativos, ao mesmo tempo em que houve um aumento da confiança no noticiário. Nesse ponto, surgem mais perguntas do que respostas. O fato de haver redução de uso do jornal como meio informativo indica que, futuramente, esse veículo se tornará substituível por outras mídias? Se se reduz o número de leitores de jornais (uma tendência mundial), os que ficam são apenas aqueles que admiram o veículo? No ano eleitoral, os jornais foram bem sucedidos em capturar a atenção dos brasileiros, tornando-se peça essencial na formação da opinião pública? Os próximos dados jogam algumas luzes sobre essas questốes.

\footnotetext{
2 Informação fornecida pela Secom, em comunicação pessoal: "Na PBM 2105, julgou-se internamente que não seria absolutamente necessário repetir a bateria de perguntas sobre o principal problema do país, assim como outras perguntas relacionadas aos hábitos de mídia dos brasileiros presentes no questionário da PBM 2014. Ao mesmo tempo, foram incluídas novas perguntas que, sob nossa visão, permitiram entender melhor como esses mesmos hábitos de consumo de mídia se estruturam” (SECOM, 2015).
} 
Gráfico 2 - Confiança: imprensa nacional

\section{Confiança - Imprensa nacional}

$$
\text { ๑ } 2014 \square 2015
$$

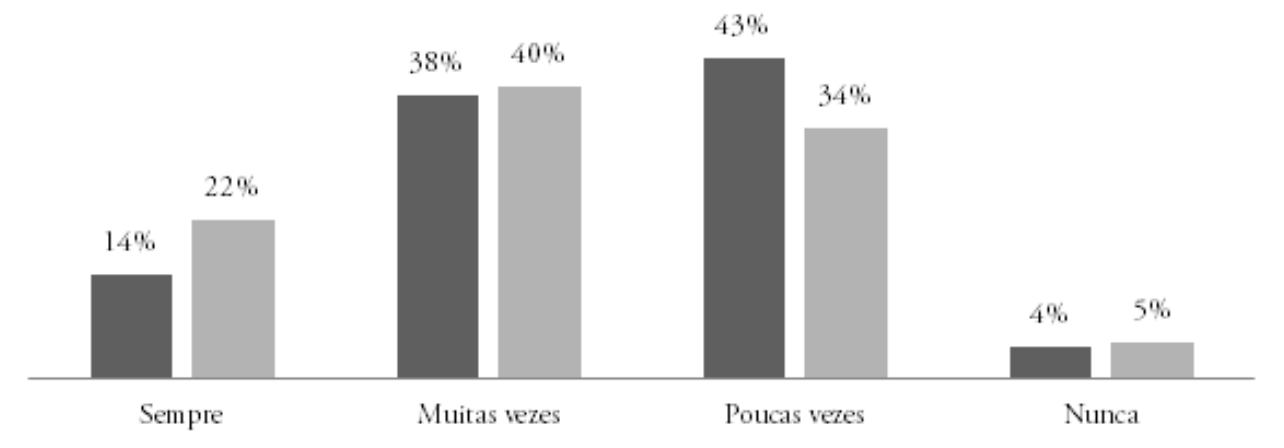

Fontes: Pesquisa Brasileira de Mídia 2014 e 2015 (BRASIL, 2013 e 2014).

Gráfico 3 - Confiança: imprensa regional ou local

\section{Confiança - Imprensa regional ou local}

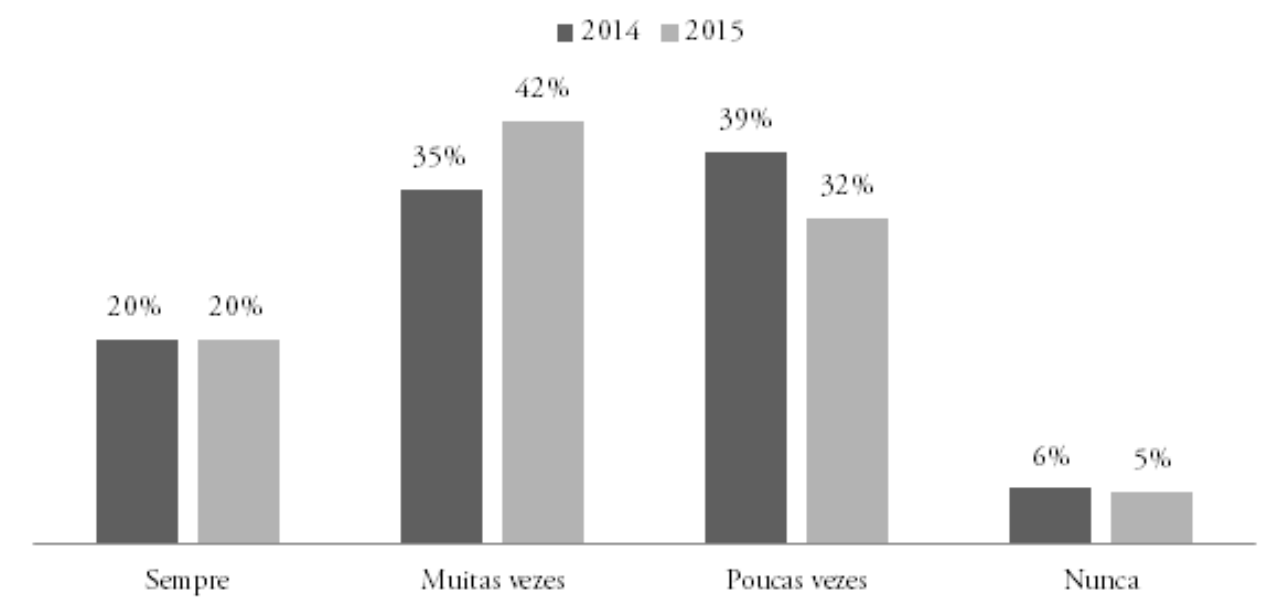

Fontes: Pesquisa Brasileira de Mídia 2014 e 2015 (BRASIL, 2013 e 2014).

O leitor de jornais possui enorme desconfiança em relação ao noticiário publicado nas redes sociais: 66\% para os jornais regionais ou locais e $76 \%$ para os nacionais. É uma tendência já apontada na PBM 2014. E é um dado que não chega a causar surpresa, mas que se contraposto a novas informaçóes da pesquisa de 2015 indica algo preocupante. Mais da metade dos leitores de jornais impressos (ou mesmo na versão digital) declarou ter o costume de se informar por meio de sites, blogs ou 
redes sociais, sendo que um terço deles usa o Facebook com essa finalidade. E mais de $40 \%$ tem o hábito de compartilhar notícias que leu ou assistiu em sites, blogs ou redes sociais. Porém, menos de $10 \%$ dos usuários de Facebook que são leitores dos impressos afirma que se informa por meio de notícias compartilhadas.

Nesse processo de transiçáo do impresso para o digital, que ocorre tanto para os jornais nacionais quanto os regionais ou locais e também mundialmente, a internet se torna um enorme desafio. Leitores de jornais estariam trocando a informaçáo que antes recebiam dos veículos preferidos por posts ou comentários de amigos relacionados ao noticiário? Se as notícias compartilhadas nas redes sociais não interessam a eles, como estariam se informando então? Assim, conforme cresce o número de pessoas que trocam a fonte de informaçáo do jornal pela internet (sites, blogs ou redes sociais), já se pode dizer que os veículos de comunicação têm uma árdua tarefa pela frente para ampliar seu público-leitor.

Tabela 1 - Fontes de informação e compartilhamento de notícias

\begin{tabular}{c|c|c|c}
\hline & $\begin{array}{c}\text { Informa-se por sites, } \\
\text { blogs ou redes sociais }\end{array}$ & $\begin{array}{c}\text { Compartilha } \\
\text { notícias }\end{array}$ & $\begin{array}{c}\text { Informa-se no Facebook } \\
\text { por meio de notícias } \\
\text { compartilhadas }\end{array}$ \\
\hline Nacional & $59 \%$ & $41 \%$ & $6 \%$ \\
\hline Regional ou local & $53 \%$ & $41 \%$ & $4 \%$ \\
\hline
\end{tabular}

Fonte: Pesquisa Brasileira de Mídia 2015 (BRASIL, 2014).

Em termos de assuntos mais consumidos, a maioria dos leitores de Folha de $S$. Paulo, O Globo e O Estado de S. Paulo prefere as notícias de política brasileira, cidades, esportes e economia. Essas quatro divisóes superam os $50 \%$ dos assuntos mais lidos e pertencem às chamadas editorias que as redaçóes costumam adotar, assim como os cadernos nos quais separam os textos jornalísticos. Na pesquisa com coleta de dados em 2013, a política ficava de fora, aparecendo apenas na sexta posição. Mas o fator eleição presidencial alterou os resultados no ano seguinte. Já os quatro assuntos mais lidos pelo leitor da imprensa regional exclui a política, que aparece abaixo de cidades, esportes, classificados e notícias policiais.

Jornais regionais ou locais recorrem ao conteúdo das Agências Folha, Estado e O Globo para preencher suas páginas, sobretudo as de política e economia, reproduzindo o discurso midiático dos três principais veículos de comunicação. Pesquisadores já alertavam sobre a tendência de a mídia local reproduzir a grande imprensa, dedicando amplos espaços para notícias nacionais e internacionais. "Muitos jornais locais tendem a se ocupar mais de assuntos comumente tratados pelos jornais 
de circulação nacional do que com assuntos específicos locais que demandariam apuração jornalística", identifica Peruzzo (2005, p. 81-82). Wolf (2008) já mostrava a inevitabilidade da ampliação do uso de agências para a produçáo da informação cotidiana, sobretudo pelo fator de barateamento do processo produtivo, mas que esse caminho levava a uma homogeneização da notícia no conjunto das publicações. $\mathrm{O}$ autor, inclusive, denominava esse conteúdo como "unidades-notícias", que serviam de alertas para as redaçóes sobre tudo o que acontece e acabavam por orientar e moldar a cobertura geral da mídia.

Questionados sobre os principais problemas do Brasil, nos meses de outubro e novembro de 2013, os leitores dos jornais nacionais indicavam, nesta ordem, saúde, educação, corrupção e administração pública (57,9\% dos apontamentos). Já os leitores da imprensa regional ou local apontavam saúde, corrupção, educação e drogas (60,9\%). Saúde, educação, salários, inflação/custo de vida e corrupção $(48,2 \%)$ são os principais problemas que afetam diretamente a vida dos leitores dos jornais nacionais, enquanto para os de títulos regionais ou locais essa ordem se altera um pouco: saúde, educação, segurança pública/violência, corrupção, educação e inflação/custo de vida $(57,3 \%)$.

As duas questôes acima e as respectivas respostas indicam que a imprensa, de maneira geral, vem oferecendo em suas páginas os principais assuntos que interessam ao leitor, mas isso não contradiz com a informação já apresentada de que o noticiário dos jornais impressos vem perdendo saliência e impacto no mundo digital. Estas duas questôes não voltaram a ser aplicadas na PBM 2015, mas os resultados da pesquisa de 2014 indicam que não há diferenças substanciais nos temas que os leitores consideram ser os principais problemas brasileiros e quais deles mais afetam suas vidas.

Muito embora pode-se refletir que se os jornais acabam homogeneizando o seu conteúdo a partir da lógica das "unidades-notícias", o que os dados das PBMs acabam corroborando, e se os mesmos estariam em franca decadência, como ventilam alguns devido à redução do número de leitores que as mídias impressas perdem diariamente, então não seria relevante estudá-los, pois estariam, talvez, com os dias contados. Este autor não compactua com essa visão e considera que a transição, lenta e dolorosa, para o mundo digital será feita tanto pela imprensa nacional quanto a regional ou local. Abre-se, na verdade, uma oportunidade única para que o atual modelo do sistema midiático brasileiro que limita a ampliação de vozes da sociedade não seja reproduzido, contribuindo para que a pluralidade de opiniôes, a diversidade regional e o contexto local tenham expressividade. Em última instância, é a qualidade da democracia que está em jogo. 
Constituída por dezenas de milhares de pequenas e médias publicaçôes e emissoras, e mesmo que individualmente algumas atinjam um público reduzido na comparação com o que se convenciona chamar de grande imprensa, o jornalismo regional ou local é um tema de importância por possuir uma penetração capilar em seus espaços, atuar de forma mais livre em períodos eleitorais e nem sempre respeitar os cânones da objetividade jornalística. Dados oficiais indicam que, desde o primeiro ano do governo de Luiz Inácio Lula da Silva, está em curso uma estratégia de desconcentração de recursos destinados à publicidade governamental do Executivo, destacando-se o incremento dado à mídia regional.

Em 2000, 91\% dos investimentos estavam nos jornais de capitais e 9\% no interior, percentuais que passaram para $80 \%$ nas capitais e 20\% no interior em 2011, apontou Messias (2013). No site da Secom, é possível ver como se deu a evoluçáo do cadastro de veículos. Em 2003, 179 jornais brasileiros faziam parte dos planos de mídias da publicidade oficial. Em 2014, esse número saltou para 2.791 títulos (SECOM, 2012).

Incluindo outras mídias, vê-se que a pulverização da verba publicitária é, de fato, uma novidade no Brasil. No fim do segundo mandato de Fernando Henrique Cardoso, ela era destinada a 499 veículos, de 182 municípios, enquanto que no fim do governo Lula os recursos passaram a ser distribuídos entre 8.094 veículos (jornais, revistas, rádio, TV, sites e blogs da internet), como aponta Rodrigues (2010). Em números atualizados até 2014, já no governo de Dilma Rousseff, eram 10.787 veículos cadastrados na Secom.

Feita essa necessária digressão, a presente análise prossegue para buscar alguma compreensão sobre as preferências de assuntos, editorias mais lidas, confiabilidade no noticiário e nas mídias. Vale a pena analisar os recortes de renda e idade da última PBM, que seguem tendência já apontada na edição 2014 (os dados do gráfico de renda foram agrupados para facilitar a leitura). 
Gráfico 4 - Renda familiar dos leitores

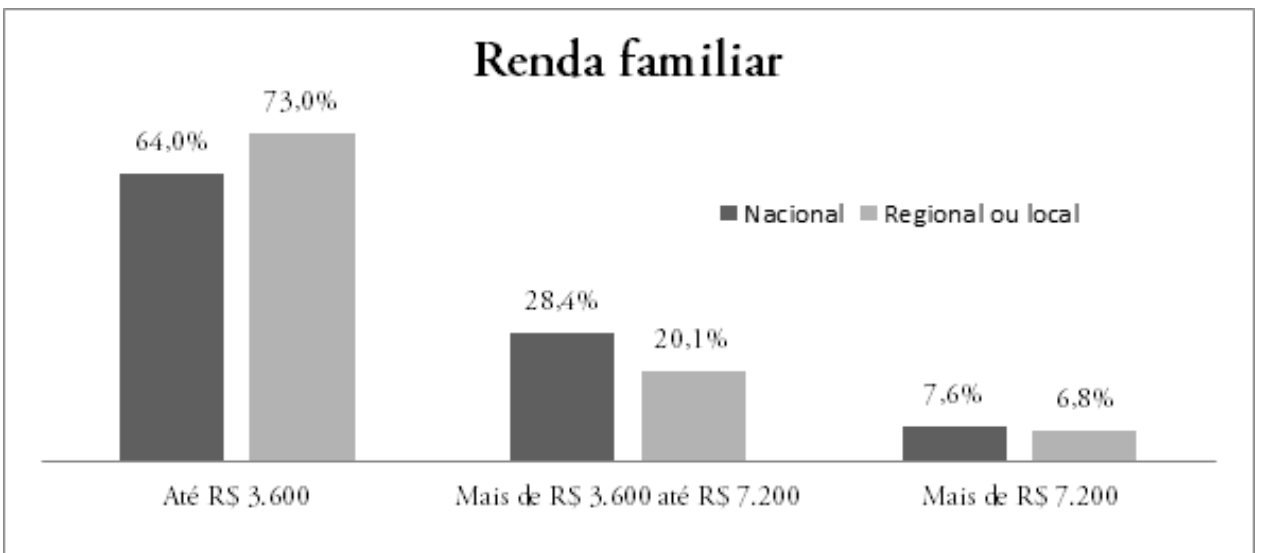

Fonte: Pesquisa Brasileira de Mídia 2015 (BRASIL, 2014).

Gráfico 5 - Faixa etária dos leitores (em anos) em contraste à da população brasileira

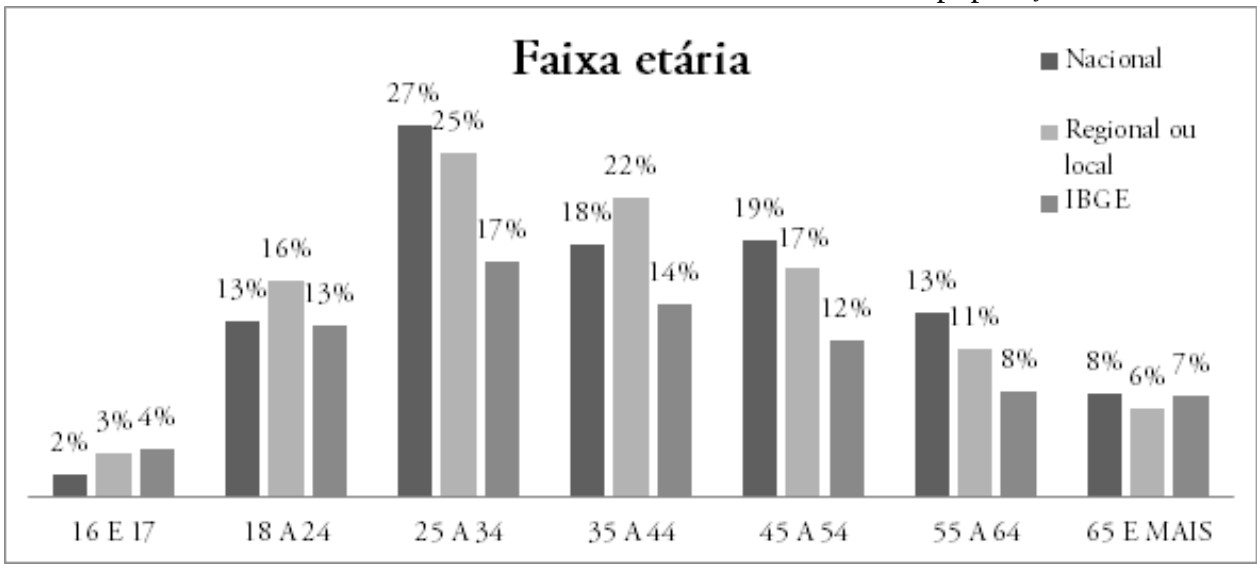

Fonte: Pesquisa Brasileira de Mídia 2015 (BRASIL, 2014); IBGE (2010).

No quesito renda, nota-se que os leitores de jornais fora do eixo Rio-São Paulo atendem mais ao perfil de classe média, enquanto há uma proporção maior de quem possui renda elevada para os leitores dos três veículos impressos de circulação nacional. Já no de idade, o que se vê é que não há diferenças significativas para os grupamentos de imprensa nacional e regional ou local, mas existem em relaçáo à proporção da população brasileira. Contrapondo os dados da PBM com o Censo 2010, o que se percebe é que na extensa faixa de 25 a 54 anos, há muito mais leitores do que a proporção de brasileiros. Ou seja, a quantidade de leitores de jornais não acompanha a da população. Em particular, temos de considerar que nessa idade ativa as pessoas trabalham e precisam estar informadas. 
Uma informação extraída a partir de um recorte de idade suscita outras questôes. É muito mais relevante a força da internet para a faixa de 18 a 24 anos entre todos os entrevistados que apontaram ler algum veículo impresso. Este é o público de potenciais assinantes no futuro. No Gráfico 1, já havíamos apontado que, de maneira geral, os leitores estáo recorrendo à internet como veículo que o brasileiro mais usa para se informar. Nesta faixa de jovens, os leitores da imprensa nacional já consideram a rede mundial de computadores como o mais importante veículo de informação $(40,9 \%)$, acima da televisão $(36,4 \%)$. Para os da imprensa regional ou local, onde a TV ainda lidera, o uso da internet para se informar é seis vezes maior que o de um jornal.

Gráfico 6 - Onde os jovens se informam mais

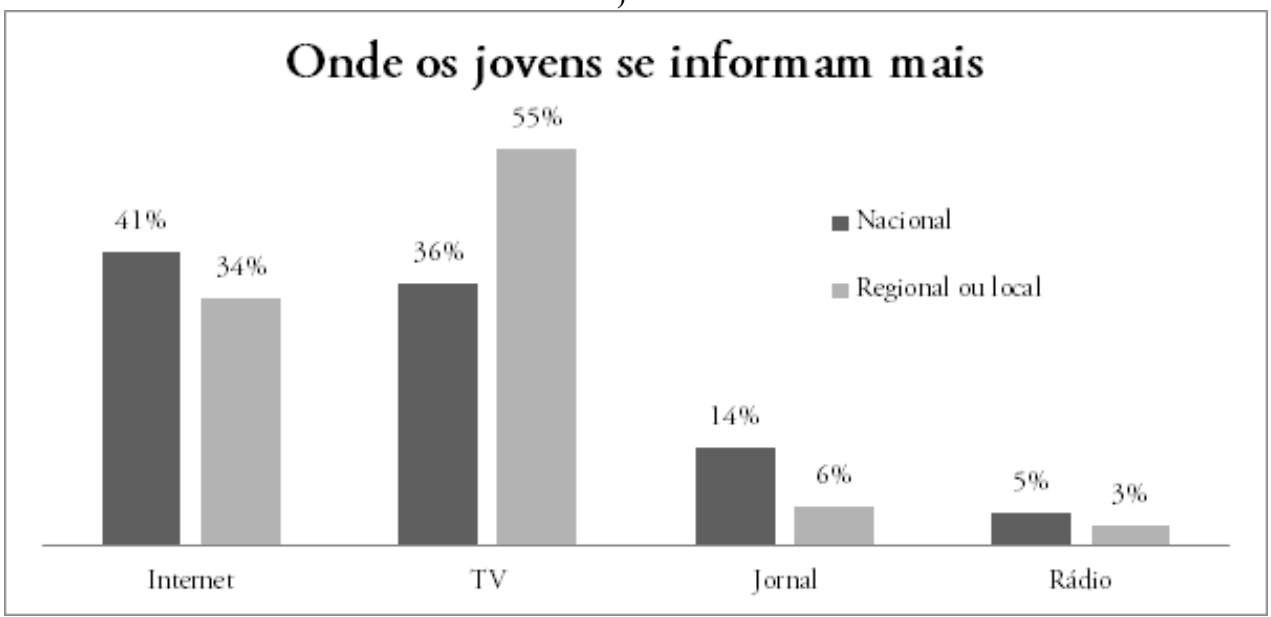

Fonte: Pesquisa Brasileira de Mídia 2015 (BRASIL, 2014).

Para descobrir se essa diferença é estatisticamente significativa, o passo seguinte foi controlar a diferença do uso de mídia entre os jovens a partir da variável renda. Como apontado no Gráfico 4, a renda familiar entre os leitores de veículos regionais ou locais é inferior ao dos três jornais de circulação nacional. Para a amostra deste corpus, o número de leitores dos três jornais nacionais de 18 a 24 anos (44 entrevistados) não pode ser considerado estatisticamente significativo, tanto que $100 \%$ dos que têm renda familiar superior a 7.200 reais diziam consumir notícias apenas pela internet, ignorando as mídias TV, rádio e jornal.

Mas para o recorte de jovens que leem preferencialmente os jornais regionais ou locais a amostra pode ser considerada significativa e ela legitima os dados apresentados no Gráfico 6. O que se vê é que quanto menor a renda, maior a predisposição de o leitor de impressos optar pela TV em detrimento da internet para 
se informar. A curva se inverte conforme se aumenta a renda da família, como se pode ver no gráfico seguinte.

Gráfico 7 - Uso de mídia entre jovens de 18 a 24 anos

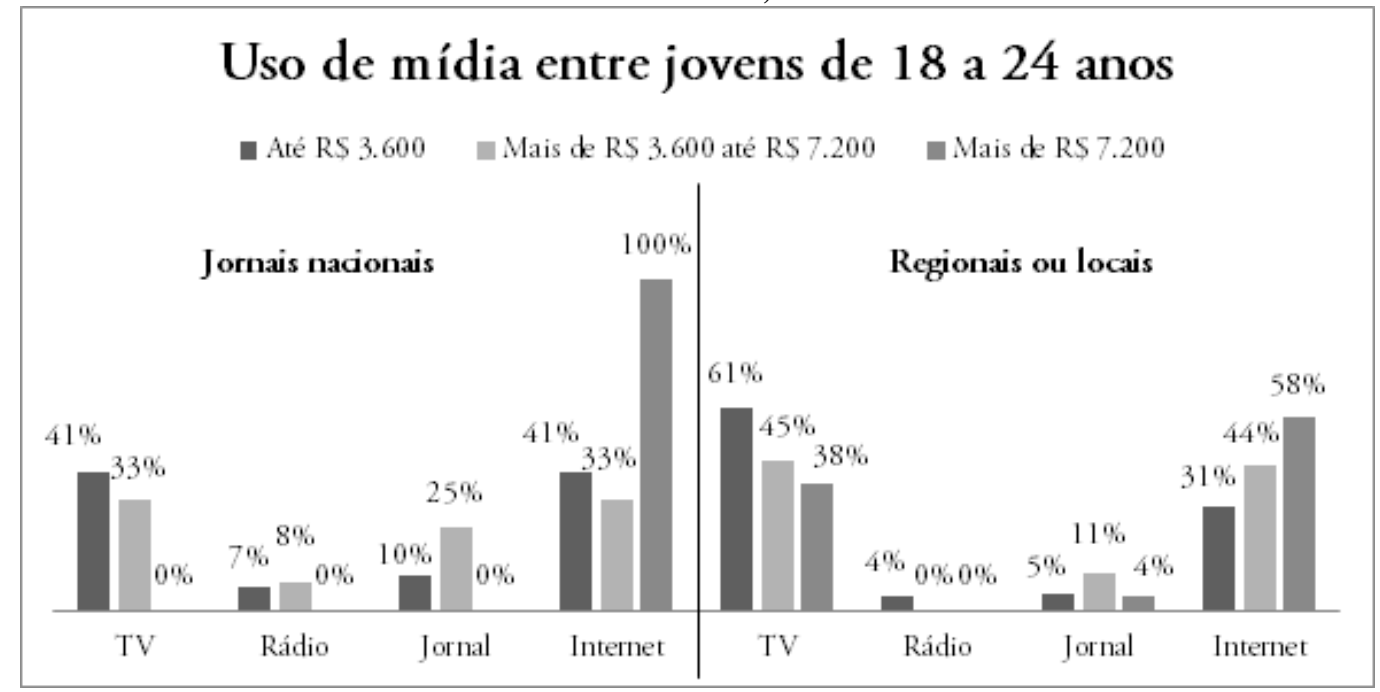

Fonte: Pesquisa Brasileira de Mídia 2015 (BRASIL, 2014).

Interessou-nos, em seguida, verificar como o público dos impressos avalia o governo federal. Essas duas questôes foram apresentadas aos entrevistados nas duas PBMs e, para este artigo, cruzadas para aferir se havia diferenças entre os dois públicos. Os leitores dos três principais jornais diminuíram a avaliação ótimo/bom (dados agrupados) e aumentaram as de regular e de ruim/péssimo, indicando uma piora no intervalo entre as duas pesquisas. Efeito ligeiramente inverso ocorreu com a imprensa regional ou local, que apresentou aumento da avaliação positiva (ótimo/bom) e redução da negativa (regular ou ruim/péssimo). 
Gráfico 8 - Avaliaçáo do governo federal

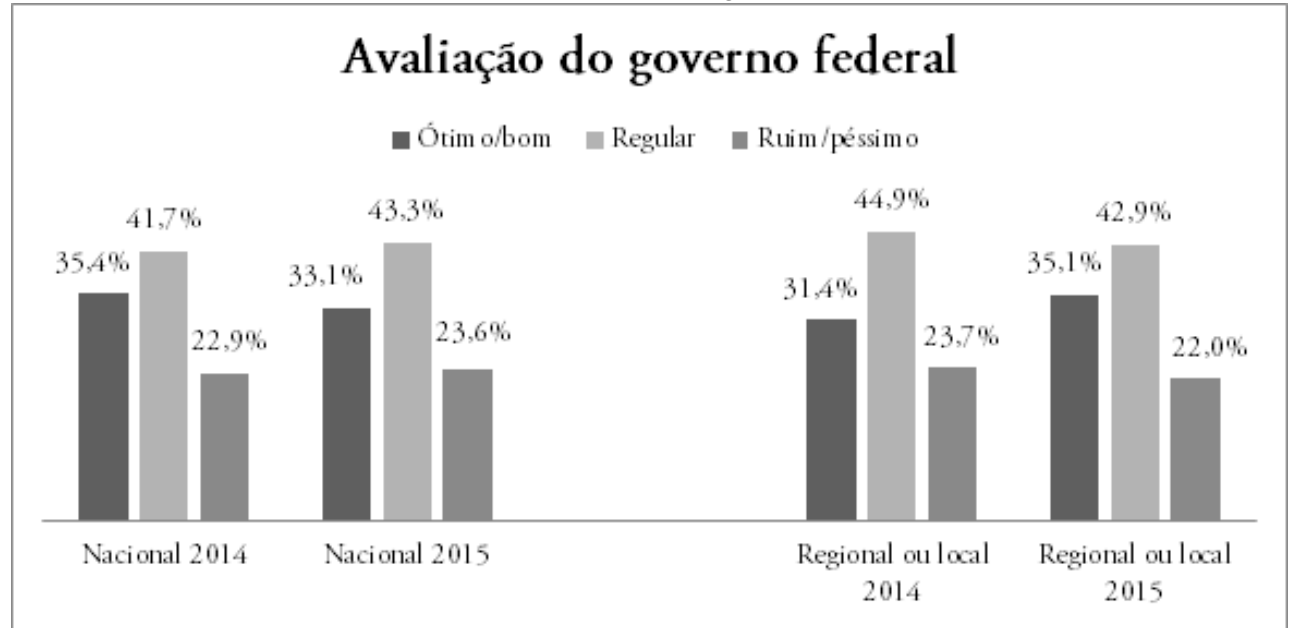

Fontes: Pesquisa Brasileira de Mídia 2014 e 2015 (BRASIL, 2013 e 2014).

Pesquisas de "Índice de Viés" realizadas pelo Laboratório de Estudos de Mídia e Esfera Pública, ligado à Universidade do Estado do Rio de Janeiro (MANCHETÔMETRO, 2014), indicam uma tendência de um aumento do noticiário mais crítico por parte de Folha de S. Paulo, O Globo e Estadáo no ano eleitoral. O projeto aponta que o índice de viés das capas dos três jornais tem ficado negativo desde janeiro de 2014 com base na fórmula número de manchetes favoráveis menos as contrárias dividindo-se o resultado pelas neutras. Mas como não há dados sobre o viés da cobertura da imprensa regional ou local, não podemos supor que esse fator de cobertura mais crítica contribuiu para a redução da avaliação do governo por parte dos leitores da imprensa nacional. É apenas uma hipótese plausível, mas que merece ser estudada com mais profundidade.

Prosseguindo, apresentamos o gráfico que mostra a distribuição dos 3.766 brasileiros deste corpus da pesquisa, referentes à PBM 2015, segundo a escolaridade de cada grupamento. Nota-se, como principal destaque, que os leitores dos jornais de circulaçáo nacional possuem mais anos de estudo do que os de publicaçóes regionais ou locais. 
Gráfico 9 - Escolaridade dos leitores

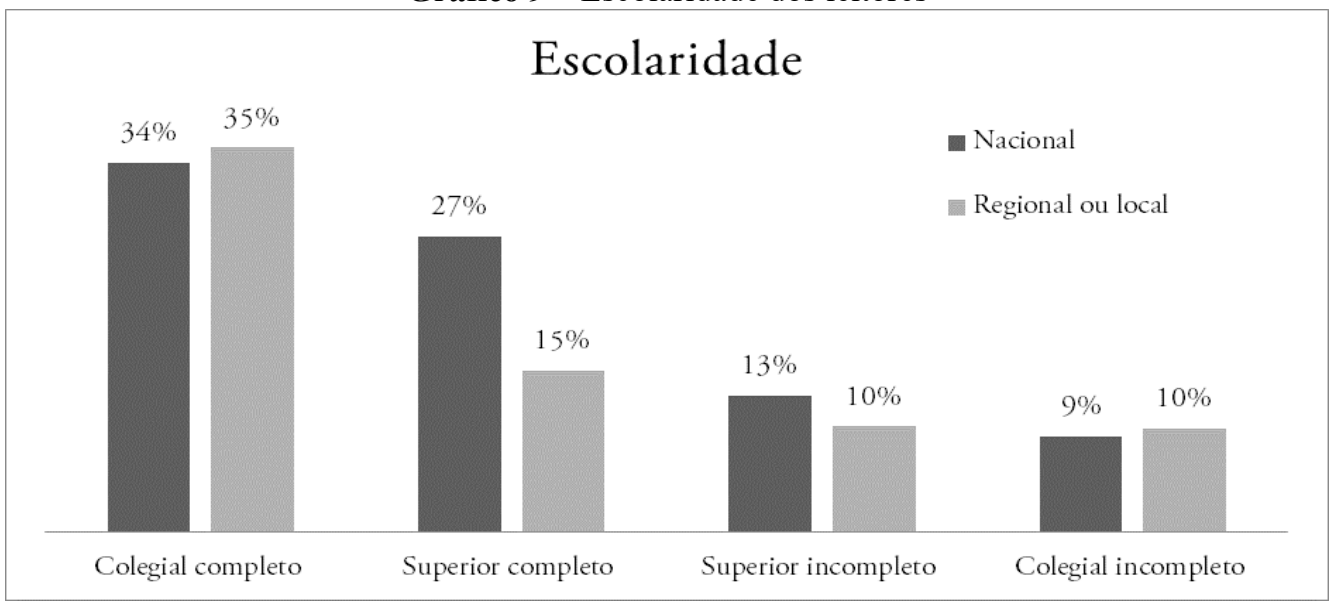

Fonte: Pesquisa Brasileira de Mídia 2015 (BRASIL, 2014).

A PBM permite ainda detectar diferenças de consumo de jornais entre os leitores da imprensa nacional e regional ou local. Como cada entrevistado podia apontar nomes diferentes para os veículos impressos que lia de segunda a sexta-feira e nos fins de semana, procuramos ver se há um comportamento diferente entre os dois grupamentos para a PBM 2015 - em 2014, a tendência era a mesma. No gráfico abaixo, percebe-se que o leitor da imprensa nacional lê preferencialmente um dos três jornais em todos os dias da semana, só de segunda a sexta-feira, ou só aos fins de semana, como esperado. Mas pelo menos um terço alterna a leitura desses órgáos de comunicação com algum título regional.

Gráfico 10 - Que tipo de jornal lê mais (imprensa nacional)

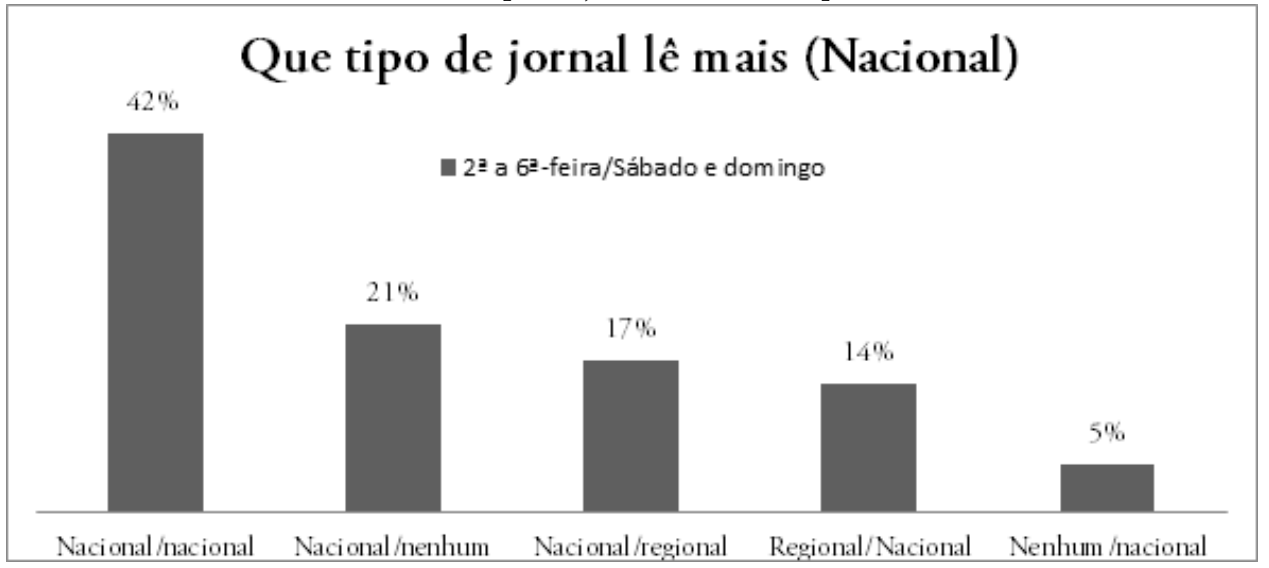

Fonte: Pesquisa Brasileira de Mídia 2015 (BRASIL, 2014). 
Isso não ocorre no caso da imprensa regional ou local. É inferior a $5 \%$ o número de leitores que alternam o seu jornal favorito conforme o dia da semana. A grande maioria lê só o veículo de sua cidade ou região, não consumindo os títulos nacionais.

Gráfico 11 - Que tipo de jornal lê mais (imprensa regional ou local)

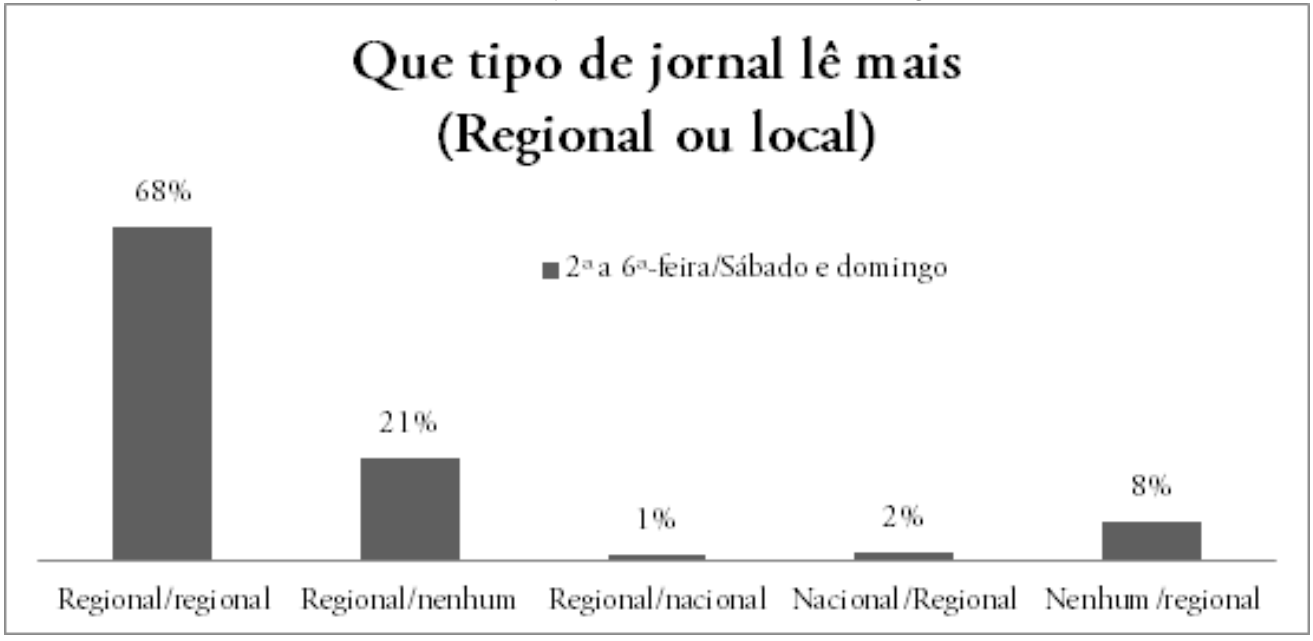

Fonte: Pesquisa Brasileira de Mídia 2015 (BRASIL, 2014).

Uma possível explicação para essa divergência seja a mobilidade dos leitores. Quem lê um dos três jornais nacionais costuma viajar para cidades fora das capitais, seja por viagens ou possuir uma segunda casa no interior ou na praia onde costuma ir aos fins de semana. Este é um fenômeno mais visível do que o inverso. Isso faz com que essa pessoa leia jornais outras regióes ou localidades.

\section{Conclusão}

Há diferenças significativas entre os leitores de jornais de circulação nacional e da mídia regional ou local. Embora pareça óbvia tal constatação, é preciso dizer que ela não era expressa dessa forma em inúmeras análises até hoje realizadas. A inexistência de estudos de recepção representativos do conjunto da população faz com que pesquisas acadêmicas e mesmo privadas projetassem para o sistema midiático do Brasil uma realidade que deveria ser restringida ao público da imprensa nacional. Os hábitos de consumo apresentados pela $\mathrm{PBM}$, mesmo náo sendo um estudo de recepção, mas antes uma pesquisa que mostra a forma como os brasileiros interagem com as mídias comunicativas, corroboram a necessidade de se observar com outros 
olhares os subsistemas midiáticos fora dos grandes centros urbanos, conforme defende Pinto (2013, p. 104).

Essas distinçóes são expressivas porque dizem respeito a categorias como idade, faixa de renda, nível de escolaridade, índice de confiança, mídias consideradas mais relevantes e/ou informativas, assuntos preferidos. Isso não significa, contudo, que não haja intercâmbios de conteúdo entre esses discursos midiáticos. A imprensa nacional continua a ter grande influência sobre a populaçáo, de forma direta (por meio dos leitores) ou indireta (pelos veículos regionais que reproduzem o seu discurso ou a forma como a notícia é produzida).

A PBM indica que o leitor fora do eixo Rio-São Paulo, e mais especificamente quem não lê Folha de S. Paulo, O Globo ou Estadão, demanda olhares mais locais, que respeitem a cultura e a diversidade regional. A instância de recepção deve ser tratada segundo suas especificidades. Um leitor de um jornal do interior quando decide consumir o conteúdo produzido por sua mídia preferida não deve sempre se pautar pelo que a imprensa nacional diz. Se este precisa de alguma informaçáo de fora de sua regiáo, veiculada ou não por algum jornal de circulação nacional, ele pode recorrer à internet - e já está fazendo isso. Mas a lógica de impor conteúdos nacionais fabricados segundo a ótica dos grandes veículos de comunicação já não encontra ressonância na grande parte do Brasil.

Eduardo Nunomura é Professor da Unversidade Metodista de São Paulo e Jornalista. Doutorando e mestre em Ciências da Comunicação da Universidade de São Paulo. E-mail: nunomura@usp.br.

\section{Referências}

BRASIL. Presidência da República. Secretaria de Comunicação Social. Pesquisa Brasília de Mídia 2014: hábitos de consumo de mídia pela população brasileira. Brasília: Secom, 2013.

BRASIL. Presidência da República. Secretaria de Comunicação Social. Pesquisa Brasília de Mídia 2015: hábitos de consumo de mídia pela população brasileira. Brasília: Secom, 2014.

CHARAUDEAU, Patrick. Discurso das mídias. 2. ed. São Paulo: Contexto, 2012.

FABBRI JUNIOR, Duílio. Problemas e desafios de um portal regional. In: FADUL, Anamaria; GOBBI, Maria Cristina (Org.). Mídia e Regiāo na era digital: diversidade cultural, convergência midiática. São Paulo: Arte \& Ciência, 2006. p. 137-145. 
FADUL, Anamaria. Mídia Regional no Brasil: elementos para uma análise. In: FADUL, Anamaria; GOBBI, Maria Cristina (Org.). Mídia e Região na era digital: diversidade cultural, convergência midiática. São Paulo: Arte \& Ciência, 2006. p. 23-40.

IBGE. Contas Nacionais, 2012. Disponível em: <http://www.ibge.gov.br/home/estatistica/economia/contasregionais/2012/default_xls_2002_2012.s htm>. Acesso em: 21 set. 2015.

Estatística da população brasileira, 2010. Disponível em: <http://www.ibge.gov.br/home/estatistica/populacao/censo2010/indicadores_sociais_municipais/tab elas_pdf/tab1.pdf>. Acesso em: 25 set. 2015.

MANCHETÔMETRO. Laboratório de Estudos de Mídia e Esfera Pública. Rio de Janeiro, 2014. Disponível em <http://www.manchetometro.com.br/>. Acesso em 25 set. 2015.

MESSIAS, Bocorny Roberto. Transparência e a desconcentração na publicidade do governo federal. Observatório da Imprensa, São Paulo, v. 13, n. 742, abr. 2013. Disponível em: $<$ http://www.fndc.org.br/clipping/transparencia-e-a-desconcentracao-na-publicidade-do-governofederal-891761/>. Acesso: 25 set. 2015.

PERUZZO, Cicilia M. Krohling. Mídia regional e local: aspectos conceituais e tendências. Comunicação \& Sociedade, São Bernardo do Campo, v. 26, n. 43, p. 67-84, 2005.

PINTO, Pâmela Araújo. Mídia regional: nem menor, nem maior, um elemento integrante do sistema midiático do Brasil. Ciberlegenda, Rio de Janeiro, n. 29, p. 95-107, 2013.

RODRIGUES, Fernando. "Lula coloca publicidade estatal em 8.094 veículos". Folha de S. Paulo, p. A-4, 28 de dezembro de 2010. Disponível em: < http://www1.folha.uol.com.br/fsp/poder/po2812201002.htm>. Acesso: 12 nov. 2015.

SECOM. Regionalização. Brasília, 15 maio 2012. Disponível em <http://www.secom.gov.br/atuacao/midia/resultados-da-comunicacao-regionalizada-2013-2012>. Acesso em 21 set. 2015.

SECOM. Pesquisa Brasileira de Midia 2015 - COM ANEXO [mensagem pessoal]. Mensagem recebida por<nunomura@usp.br>em 13 jul.2015.

THOMPSON, John B. A midia e a modernidade: uma teoria social da mídia. 15. ed. Petrópolis: Vozes, 2014.

WOLF, Mauro. Teorias das comunicações de massa. 3 ed. São Paulo: Martins Fontes, 2008.

Texto recebido em 27 de setembro de 2015 . Aprovado em 09 de novembro de 2015. 